\title{
Tehran dentists' knowledge and attitudes towards hepatitis $B$ and their willingness to treat simulated hepatitis B positive patients
}

B. Khosravanifard, ${ }^{1}$ V. Rakhshan, ${ }^{2}$ L. Najafi-Salehi ${ }^{3}$ and S. Sherafat ${ }^{3}$

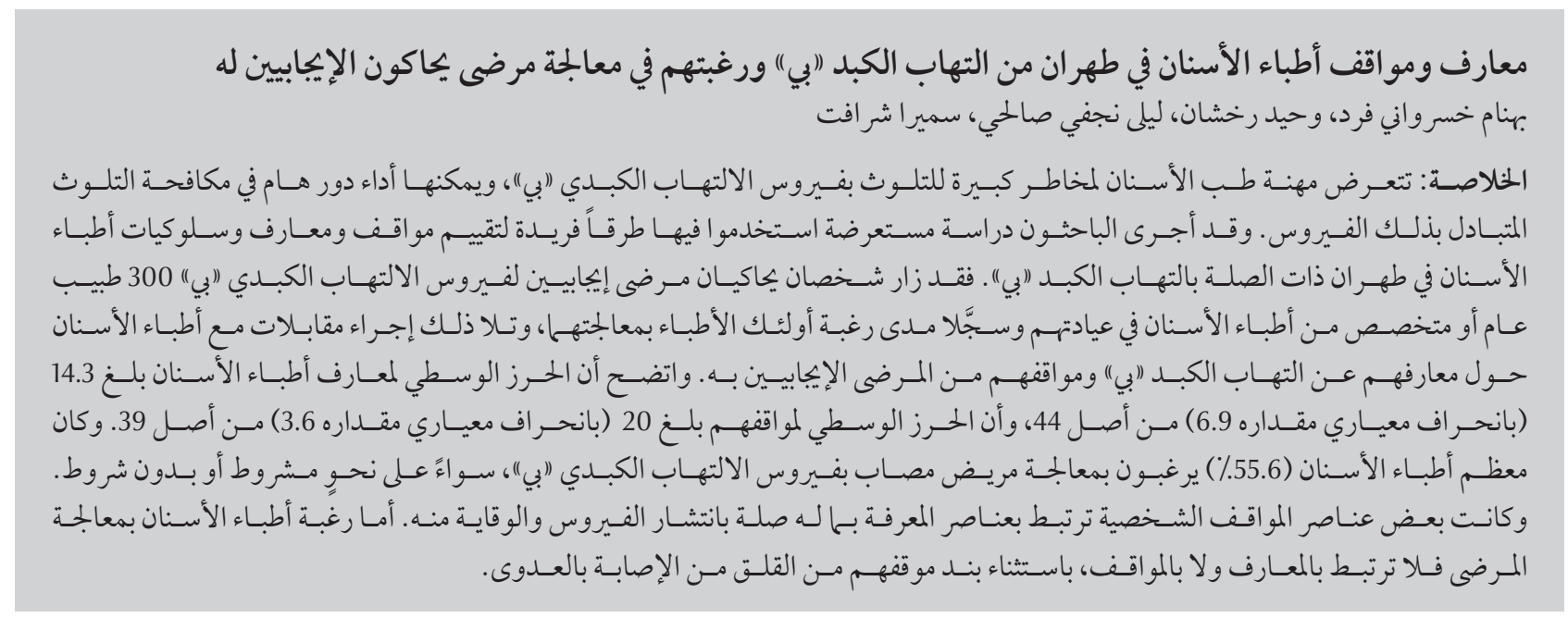

ABSTRACT The dental profession has a high risk of hepatitis B virus (HBV) contamination and can play a crucial role in controlling HBV cross-contamination. In this cross-sectional study we used unique methods to assess Tehran dentists' knowledge, attitude and behaviour regarding HBV. Two simulated HBV-positive patients visited 300 general/specialist dentists in their offices and recorded dentists' willingness to treat them. Later, the dentists were interviewed regarding their knowledge about hepatitis B and attitude to HBV-positive patients. The mean knowledge score of dentists was 14.3 (SD 6.9) out of 44 and the mean attitude score was 20.0 (SD 3.6) out of 39. A majority of dentists (55.6\%) were willing to treat a patient with HBV, unconditionally or with conditions. Some individual attitude items correlated with knowledge items concerning transmission of the virus and its prevention. Dentists' willingness to treat patients did not correlate with knowledge or attitude, except for the attitude item on concern about becoming infected.

Connaissances et attitudes des dentistes de Téhéran par rapport à I'hépatite $B$ et disposition de ces derniers à traiter des patients déclarant une infection fictive à I'hépatite $B$

RÉSUMÉ La profession dentaire est à haut risque de contamination par le virus de l'hépatite B et peut jouer un rôle crucial dans la lutte contre la contamination croisée par ce virus. Dans cette présente étude transversale, des méthodes uniques ont été adoptée pour évaluer les connaissances, les attitudes et les comportements des dentistes de Téhéran vis-à-vis du virus de l'hépatite B. Deux patients déclarant une infection fictive par le virus de l'hépatite B ont rendu visite à 300 dentistes spécialistes ou généralistes sur leur lieu d'exercice et ont pris note de leur disposition à les traiter. Dans un deuxième temps, les dentistes ont été interrogés sur leurs connaissances en matière d'hépatite B et leur attitude vis-à-vis des patients infectés par le virus. Le score moyen des dentistes pour les connaissances était de 14,3 (ET 6,9) sur 44 tandis que le score moyen pour l'attitude était de 20,0 (ET 3,6) sur 39. La majorité des dentistes $(55,6 \%)$ étaient disposés à traiter un patient infecté par le virus de l'hépatite $B$, avec ou sans conditions. Certains items concernant l'attitude individuelle étaient corrélés aux items concernant les connaissances relatives à la transmission du virus et sa prévention. La disposition des dentistes à traiter des patients infectés n'était pas corrélée aux connaissances ni à l'attitude, à l'exception de l'item concernant l'attitude relative à la crainte de contracter l'infection. 


\section{Introduction}

Dentists are exposed to numerous blood-borne diseases, including hepatitis B (1-8), which is the most serious type of viral hepatitis and a major global public health issue $(1,4,9-11)$. Although hepatitis B has no oral manifestations, it is of great concern to the dental profession due to the ease of transmission of the virus $(11,12)$. Dental staff are 2.5 to 10 times more likely than the general population to become infected with hepatitis $B$ virus (HBV), and they have the highest risk among all fields of health-care providers because they are in contact with contaminant fluids, droplets, aerosols and small sharp instruments $(1-8,13)$. Many dentists could therefore be reluctant or unwilling to treat HBV-positive patients due to the high exposure risks $(4,14)$ and extra difficulties in dealing with them. Furthermore, identifying those capable of transmitting $\mathrm{HBV}$ is difficult, since many infected patients may be unaware of their carrier status, may be asymptomatic or simply may not want to disclose their infectious condition (12). Hence, dentists need to be extra cautious, especially as vaccination cannot guarantee immunoprotection $(1,4,6,13,15)$, not to mention that many dentists/physicians do not even attempt to receive it $(1,5,6,13)$.

Dentists' discriminatory behaviour against patients with certain conditions is ethically (and, in some countries, legally) unacceptable $(4,16)$. However, even in North America, where there are strict ethical requirements to treat, many dentists still remain unwilling to treat patients suffering from bloodborne infectious diseases (16). Besides being unethical/illegal, clinicians' reluctance to treat such patients can have serious public health consequences (14). Many hepatitis B patients conceal their condition (12), and dentists' negative attitudes might reinforce patients' desire to conceal, resulting in a greater risk of spread of the disease $(4,10,14)$.
The key to encouraging clinicians to treat patients with contagious diseases is not legal penalties (16) but improving their attitudes $(14,17)$. Attitudes themselves might be a reflection of improved knowledge and confidence (14,17-19). Proper knowledge of health staff about viral hepatitis transmission and prevention, and improved attitudes and willingness to treating infected patients, can assist considerably in eliminating the spread of HBV $(14,17,20)$. This is especially important in developing countries where there are high rates of hepatitis infection in the population $(11,21)$. Probing medical/dental clinicians' attitudes towards diagnosing hepatitis $\mathrm{B}$ and handling HBV-positive patients may alert policy-makers at academic, governmental and global levels to allocate educational or infection control resources more effectively. Despite the above, to the best of our knowledge, this issue has been largely ignored in the research. We therefore aimed to survey dentists' knowledge of hepatitis $B$ and its management, their practices in handling exposure to HBV, their attitudes towards hepatitis B and to HBV-infected patients and their willingness to treat such patients. Additionally, dentists' educational and professional profiles and infection control practices were evaluated. For the first time 2 methods were used for the survey-direct interviews and simulated patients - and less reliable mass-survey methods were avoided (14).

\section{Methods}

\section{Sampling}

In this 2-phase, cross-sectional study, 300 dentists and specialists were enrolled during 2009-2010 from the Medical Council list of all dentists practising in Tehran, Islamic Republic of Iran. The number of participants was determined according to the literature and our own study of dentists' knowledge, attitude and behaviour towards
AIDS (14). Using systematic, random sampling from the alphabetical list of more than 6000 registered Tehran dentists, we aimed to recruit 128 general practitioners and 72 specialists who were fully available through both phases of this study. The specialists consisted of 12 specialists from each of the following fields: periodontics, orthodontics, prosthodontics, endodontics, maxillofacial surgery and restorative dentistry. Afterwards, 100 other dentists (including 39 specialists) were enrolled not from the list but by cluster sampling from 5 residential districts of Tehran. Sampling continued until the desired sample size was reached (i.e. 300 dentists including 111 specialists). The inclusion criterion was practising dentistry in Tehran. The exclusion criteria were not being available at the scheduled session or refusal to participate at the second session. A total of 392 dentists were randomly selected and visited and/or called and 92 were excluded.

The reason for using different methods of sampling was to include both registered and unregistered dentists. The registered dentists were those who were licensed to work in Tehran. With some exceptions Iranian dentists need to work for some time in other cities before being licensed to work in Tehran. However, some unlicensed dentists do practice in Tehran under the licence of a colleague and they are not registered in the Medical Council database. The total population of unregistered dentists is not known. We were also unable to ascertain the number of unregistered dentists enrolled in this study since dentists did not disclose their licence status and ethically it was not possible to check their status without their consent.

No personal identifiers or occupational information (i.e. names, phone numbers, exact addresses or licence numbers) were collected. Ethical approval for the study was obtained from the internal review board of Islamic Azad University. In addition, the Medical Council approved our methods 
before allowing access to the list of registered dentists (14).

\section{Data collection}

First phase: direct evaluation by simulated patients

Two observers, who were female finalyear dental students aged 22 and 23 years respectively, made appointments to visit the dentists (by visiting or calling their offices) for oral examination sessions. Each observer evaluated 150 dentists. In the first session, immediately after visiting the dentist or the assistant and immediately before the oral examination, and/or when the patient's profile were being recorded, the observers claimed, both orally and in written form, to be blood-borne HBV-positive. They made sure that the dentists were fully aware of their condition (by telling them directly as well) before any examinations. Afterwards the dentists' reactions were monitored and later recorded in detail (14). The observers were trained by one researcher (B.K.), who had a similar experience with simulated AIDS patients (16). Dentists' responses and reactions were rated by the simulated patients on a Likert-scale from $0-4$, according to the following definitions: score 0 , the dentist refused to treat the patient (with or without an offensive/unfriendly tone, language or behaviour); score 1, the dentist did not agree to treat at that moment but suggested that the patient might be treated once she was totally recovered; score 2, the dentist did not agree to treat but referred the patient to another colleague; score 3, the dentist agreed to deliver dental services but on some conditions (e.g. at an available equipped clinic and/or at specific schedules and/ or at higher costs); score 4, the dentist agreed to treat the patient in the same way as a normal patient.

Second phase: direct interviews using knowledge and attitude questionnaires

After about 1 week, each observer called and visited the dentists who had been
Table 1 Educational and occupational characteristics and self-reported hepatitis B virus (HBV) infection control practices of the study sample of Tehran dentists $(\boldsymbol{n}=$ 300)

Variable

$\%$ of respondents

\section{Type of dental clinic}

Office only $\quad 66.3$

Clinic only $\quad 14.3$

Both 19.3

No. of staffemployed

1

2

Years of clinical experience

$>6$

$\leq 6$

Graduated abroad from foreign university

Total

General dentists

19.3

Specialist dentists $\quad 7.0$

Academic faculty experience $\quad 19.7$

No. of continuing education courses attended

$>3$

$1-2$

Never

Attended course(s) within previous 2 years

Main source of $\mathrm{HBV}$-related knowledge

Textbooks

Articles

33.0

Courses/classes

23.3

National media

Self-assessed knowledge regarding $\mathrm{HBV}$

Very knowledgeable

Good

57.7

Poor

31.0

Very poor

Vaccination status

Vaccinated against HBV

Had antibody titre tested

Personal protection used

Dental mask

Disposable gloves for each patient

Glasses/eyeshield

Minutes preparing dental unit for next patient

Sterilization methods used

Autoclave only

41.0

Both autoclave and dry oven

41.0

Oven only (no autoclave)

.3

(1)

3

(3.

(1)

3

9.7


surveyed by the other observer, and interviewed them face-to-face regarding their knowledge and attitudes using a structured questionnaire. The knowledge-oriented questionnaire included 18 questions regarding the diagnostic criteria of $\mathrm{HBV}$ and the management of patients (maximum obtainable score 44). The scales of the scores were determined by an expert team. The attitude-oriented questionnaire included 13 questions with 4 Likert-scale answers (scores 3-0 for each question, maximum obtainable score 39), which represented the extent of dentists' willingness to participate in treating AIDS patients (14).

The questionnaire also collected data on the dentists' demographic, educational and occupational profile, including: age; sex; office district (Tehran south, west, east, centre or north); office type (private office and/or general clinic with different departments); number of personnel working at the office; having an $\mathrm{MS} / \mathrm{PhD}$ degree in dentistry; location of graduation (undergraduate and/ or postgraduate courses and whether in an Iranian or foreign university); duration of work experience; university teaching experience; number of continuing education courses attended and time elapsed since the last continuing education course $(14,16)$. The dentists were also asked about their vaccination status (completion of 3-course HBV vaccination; checking the status of antibody to hepatitis B surface antigen status) and their infection control practices, including wearing dental mask, latex gloves and dental glasses/shield; estimated time to prepare dental unit for the next patient; and available sterilization units (autoclave, oven or both) (14).

\section{Statistical analysis}

There was high internal reliability between the knowledge score according to the Cronbach alpha (0.67). The internal agreement between the 13 attitude scores was moderate (Cronbach alpha
0.41 , which could reach to a maximum of $65 \%$ after removing 4 questions. Nevertheless, since each question was to be assessed individually, the total internal agreement was not of major concern and we preferred to keep those questions in the study in order to avoid data loss.

Descriptive statistics including percentages and mean and standard deviation (SD) of scores and standardized scores (score percentages of maximum possible scores) were calculated in each category. The correlations between scores on knowledge, attitude and behaviour of dentists were assessed using Spearman correlation coefficient in the SPSS statistical package, version 17. Also in accordance with our previous methods, the scores were stratified into poor, medium and good categories and the correlations between the categorized scores were also assessed (14). Good knowledge was defined as correct answers given to > 15 questions; average knowledge 10-15 questions; poor knowledge $<10$ questions. Attitudes were categorized into 3 groups: negative attitude (scores $<20)$, neutral attitude (scores 20-30) or positive attitude (scores 30-39) (14). The behaviour scores were also converted into 2 states of agreeing to treat (scores 3 and 4 ) and not agreeing to treat (scores 0,1 and 2) (14). The correlations between the stratified values were calculated using a Spearman correlation coefficient. The level of significance was set at 0.05 .

\section{Results}

\section{Background characteristics}

A majority of the sample of dentists were males $(211,70.3 \%)$. Mean age was 43.9 (SD 7.3) years (range 25-67 years). Most of the dental offices visited were in the northern $(38.7 \%)$ or western (23.0\%) districts of Tehran. The participants' educational and occupational characteristics and infection control practices are summarized in Table 1.
A total of $26.3 \%$ had graduated abroad from a foreign university. Self-reported infection control practices revealed that almost all dentists wore dental masks and disposable gloves for each patient, while $88.3 \%$ were vaccinated against HBV and 55.0\% had tested their antibody titre.

\section{Knowledge scores}

The mean knowledge score of dentists was 14.3 (SD 6.9) (range 0-44) (minimum $=0$, 1st quartile $=9$, median $=$ 13,3 rd quartile $=20$, maximum $=32$ ) (Table 2). Plotting the prevalence (net frequencies) of different total knowledge scores obtained by the 300 dentists indicated that lower knowledge scores close to 10 were more prevalent (Figure 1). Based on the number of questions answered, as described before (14), 83.7\% of the 300 participants were graded as having poor knowledge, $16.3 \%$ had moderate knowledge and none had good knowledge about HBV. The highest mean scores were for whether dentists should consider all patients as carriers of blood-born infectious diseases [2.62 (SD 1.00)] and the types of viral hepatitis spread in dentistry [2.19 (SD 1.33)]. The lowest score was for the question about how many viruses are required for disease transmission and the seroconversion rate $[0.18($ SD 0.41) $]$.

\section{Attitude scores}

The mean attitude score was 20.0 (SD 3.6) (range: 0-39) (minimum $=7,1$ st quartile $=18$, median $=20$, 3rd quartile $=22$, maximum $=31)($ Table 3). Plotting the net frequencies of different total attitude scores showed a higher prevalence of scores around 20 or less (Figure 2). Based on the stratification protocol described before (14), 43.3\% of participants had negative attitudes, $55.0 \%$ had average attitudes and $1.7 \%$ had positive attitudes towards HBV. The highest mean score was for the item "HBV is extremely rare, is not potentially dangerous and fear of HBV is 


\begin{tabular}{|c|c|c|c|c|c|}
\hline \multirow[t]{2}{*}{$\#$} & \multirow[t]{2}{*}{ Knowledge items } & \multirow{2}{*}{$\begin{array}{l}\text { Max. } \\
\text { score }\end{array}$} & \multirow[t]{2}{*}{ Mean (SD) score } & \multicolumn{2}{|c|}{ Significant correlation $s^{a}$} \\
\hline & & & & Attitude items & Behaviour \\
\hline K1 & $\begin{array}{l}\text { Which types of viral hepatitis are mostly spread in } \\
\text { dentistry? Which is the most common? }\end{array}$ & 3 & $2.19(1.33)$ & A7 & - \\
\hline K2 & Which HBV transmission route is the most effective? & 3 & $1.03(1.43)$ & $\mathrm{A} 3, \mathrm{~A} 5, \mathrm{~A} 7$ & - \\
\hline K3 & $\begin{array}{l}\text { How many viruses are required for HBV disease } \\
\text { transmission? What is the seroconversion rate? }\end{array}$ & 3 & $0.18(0.41)$ & - & - \\
\hline K4 & How long is the latent phase of HBV? & 3 & $0.45(0.84)$ & - & - \\
\hline K5 & What proportion of patients are carriers? & 3 & $0.54(1.15)$ & $\mathrm{A} 1$ & - \\
\hline K6 & What are malignant changes in HBV-positive patients? & 3 & $1.02(1.01)$ & - & - \\
\hline K7 & $\begin{array}{l}\text { Should dentists consider all patients as carriers of blood- } \\
\text { born infectious diseases? }\end{array}$ & 3 & $2.62(1.00)$ & A3 & - \\
\hline K8 & What are the signs of an HBV carrier in a blood test? & 3 & $0.82(1.34)$ & - & - \\
\hline K9 & Is hepatitis B antigen found in saliva of infected people? & 1 & $0.41(0.49)$ & - & - \\
\hline K10 & $\begin{array}{l}\text { How long does HBV survive in dry environments without } \\
\text { sterilization? }\end{array}$ & 1 & $0.50(0.86)$ & $\mathrm{A} 8, \mathrm{~A} 12, \mathrm{~A} 13$ & - \\
\hline K11 & $\begin{array}{l}\text { What are the accepted methods of sterilization against } \\
\text { HBV? }\end{array}$ & 3 & $1.08(1.44)$ & $\begin{array}{l}\mathrm{A} 8, \mathrm{~A} 9, \mathrm{~A} 12, \\
\mathrm{~A} 13\end{array}$ & - \\
\hline K12 & How are vaccine dose intervals scheduled? & 2 & $0.82(0.99)$ & A4, A13 & - \\
\hline K13 & $\begin{array}{l}\text { How long after vaccination against HBV can antibody titre } \\
\text { be discerned? }\end{array}$ & 3 & $0.24(0.66)$ & A5 & - \\
\hline K14 & $\begin{array}{l}\text { Under which conditions and how long after vaccination } \\
\text { should a booster dose be received? }\end{array}$ & 2 & $0.42(0.82)$ & A3, A7 & - \\
\hline K15 & What are the signs and symptoms of hepatitis? & 1 & $0.63(0.48)$ & - & - \\
\hline K16 & What are the laboratory findings of hepatitis? & 3 & $0.43(1.05)$ & $\mathrm{A} 12, \mathrm{~A} 13$ & - \\
\hline K17 & $\begin{array}{l}\text { What is the first step to take after exposure to an HBV- } \\
\text { positive patient? }\end{array}$ & 2 & $0.51(0.87)$ & - & - \\
\hline K18 & $\begin{array}{l}\text { What is the first step to take after exposure to a patient } \\
\text { with unknown HBV status? }\end{array}$ & 2 & $0.25(0.67)$ & A6 & - \\
\hline
\end{tabular}

${ }^{a}$ Spearman correlations, $P \leq 0.05 ;-=$ no significant correlations.

$S D=$ standard deviation; $A=$ attitude domain item number

due to adverse propaganda" (correct $=$ disagree) $[2.34$ (SD 0.88)]. The lowest mean score was for the item "Society should not reject or dismiss HBV patients $/$ carriers" $($ correct $=$ agree $)[0.97$ (SD 0.89)]

\section{Behaviour scores}

None of the clinicians suspected the observers were healthy researchers. The dentists' behaviour scores for willingness to treat a patient with HBV showed that $14.9 \%$ scored 4 (agreed to treat), $40.6 \%$ scored 3 (agreed to treat, with conditions), $15.5 \%$ scored 2 (referred the patient), $12.9 \%$ scored 1 (refused to treat, with conditions) and $3.8 \%$ scored 0 (refused to treat). The mean behaviour score of dentists was 2.57 (SD 1.69).

\section{Correlations}

In order to compare the scores in different domains the mean scores were converted to a percentage of the maximum possible scores (Table 4). Overall mean percentage scores were $44.2 \%$ (SD 21.6\%) for knowledge, 51.5\% (SD 9.1\%) for attitudes and 64.3\% (SD $26.7 \%)$ for behaviour. There were no significant correlations between the domains in dentists' total scores (Spearman coefficients, $P>0.05$ ).

Tables 2 and 3 show which individual items had significant correlations with items in other domains. When assessing the items separately, a few correlations between dentists' scores on the knowledge and attitudes emerged, especially with 3 of the knowledge items: question 2 ("Which HBV transmission route is the most effective?"), question 10 ("How long does HBV survive in dry environments without sterilization?") and question 11 ("What are the accepted methods for sterilization against HBV?"). Dentists' behaviour in terms of willingness to treat an HBV-positive patient did not correlate with any of the knowledge or attitude items, except for a weak correlation with question 8 of the attitude questionnaire "I hesitate to treat HBV patients/carriers out of concern of becoming infected". 
The Spearman correlation coefficient indicated a significant correlation between the knowledge and attitude scores when these were categorized as poor, medium or good ( $r$ ho $=0.133, P=$ 0.022 ). There were no correlations between the behaviour scores when these were dichotomized into agreeing or not agreeing to treat and the categorized knowledge ( $r$ ho $=-0.057, P=0.327$ ) or attitude ( $r$ o $=0.038, P=0.510)$ scores.

\section{Discussion}

Our study showed that a high proportion of this sample of dentists agreed to treat HBV-positive patients, albeit with some conditions. Although this is not ideal from an ethical point of view, it was better than what was observed in a similar study in Tehran with simulated AIDS patients (14). None of the domains (knowledge, attitude or behaviour) correlated with the other domains, when the raw scores were assessed. However, the stratified knowledge and attitude categories correlated weakly in a positive way. Interestingly, none of the knowledge or attitude scores of the dentists was associated with their behaviour score as assessed by willingness to treat a simulated patient.

Self-reported infection control protocols were practised well among Tehran dentists, comparable with previously reported rates $(5,10,16)$. Vaccination and HBV antibody titre checks agreed with the higher end of the rates reported in the literature $(1,5,6,10)$.

It has been suggested that dentists might have better knowledge of transmission routes compared with midwifery students and surgeons (10), although some studies showed that medical students had better knowledge compared with dental students (20). Many participants in this study rated themselves as having a good knowledge regarding hepatitis B. Nevertheless, their questionnaire results showed poor knowledge, especially when it came to answering important but simple questions such as those about triple-course

Table 3 Mean scores for each item of attitude to hepatitis B virus (HBV) among Tehran dentists $(\boldsymbol{n}=300)$, and correlations with knowledge items and behaviour

\begin{tabular}{|c|c|c|c|c|c|}
\hline \multirow[t]{2}{*}{ \# } & \multirow[t]{2}{*}{ Attitude items } & \multirow[t]{2}{*}{ Max. score (= 3) } & \multirow[t]{2}{*}{ Mean (SD) score } & \multicolumn{2}{|c|}{ Significant correlations $\mathrm{s}^{\mathrm{a}}$} \\
\hline & & & & $\begin{array}{l}\text { Knowledge } \\
\text { items }\end{array}$ & Behaviour \\
\hline A1 & $\begin{array}{l}\mathrm{HBV} \text { is extremely rare, is not potentially dangerous, and } \\
\text { the fear of } \mathrm{HBV} \text { is due to adverse propaganda }\end{array}$ & Strongly disagree & $2.34(0.88)$ & K5 & - \\
\hline A2 & $\begin{array}{l}\text { I would willingly examine and treat HBV patients/ } \\
\text { carriers }\end{array}$ & Strongly agree & $1.32(0.87)$ & - & - \\
\hline A3 & $\begin{array}{l}\text { I would treat HBV patients/carriers only if full } \\
\text { protection were available }\end{array}$ & Strongly disagree & $1.06(0.74)$ & $\mathrm{K} 2, \mathrm{~K} 7, \mathrm{~K} 14$ & - \\
\hline A4 & $\begin{array}{l}\text { Since my duty is to treat all dental patients, I would } \\
\text { treat HBV-positive patients/carriers as well }\end{array}$ & Strongly agree & $1.21(0.79)$ & K12 & - \\
\hline A5 & $\begin{array}{l}\text { Both healthy and HBV-positive dental patients are } \\
\text { equally respected and both deserve complete dental } \\
\text { care/treatment }\end{array}$ & Strongly disagree & $1.18(0.93)$ & K2, K13 & - \\
\hline A6 & $\begin{array}{l}\text { Society should not reject or dismiss HBV-positive } \\
\text { patients/carriers }\end{array}$ & Strongly agree & $0.97(0.89)$ & K18 & - \\
\hline A7 & $\begin{array}{l}\text { Dentists who avoid treating HBV-positive patients/ } \\
\text { carriers should be penalized }\end{array}$ & Strongly agree & $1.68(0.83)$ & $\mathrm{K} 1, \mathrm{~K} 2, \mathrm{~K} 14$ & - \\
\hline A8 & $\begin{array}{l}\text { I hesitate to treat HBV-positive patients/carriers out of } \\
\text { concern of becoming infected }\end{array}$ & Strongly disagree & $1.88(0.86)$ & K10, K11 & B \\
\hline A9 & $\begin{array}{l}\text { If clinic policies oblige me to treat HBV-positive } \\
\text { patients/carriers, I would leave practice }\end{array}$ & Strongly disagree & $1.85(0.90)$ & K11 & - \\
\hline A10 & $\begin{array}{l}\text { Since hepatitis B is not certainly curable, I may not treat } \\
\text { HBV-positive patients/carriers }\end{array}$ & Strongly disagree & $1.86(0.93)$ & - & - \\
\hline A11 & $\begin{array}{l}\text { HBV-positive patients/carriers should be charged more } \\
\text { than normal patients are }\end{array}$ & Strongly disagree & $1.75(0.88)$ & - & - \\
\hline $\mathrm{A} 12$ & $\begin{array}{l}\text { HBV-positive patients/carriers should receive dental } \\
\text { care at specific clinics }\end{array}$ & Strongly disagree & $1.41(0.96)$ & K10, K11, K16 & - \\
\hline A13 & $\begin{array}{l}\text { Asymptomatic HBV-positive carriers who do not state } \\
\text { their condition should be penalized }\end{array}$ & Strongly disagree & $1.59(0.93)$ & $\begin{array}{l}\mathrm{K} 10, \mathrm{~K} 11, \\
\mathrm{~K} 12, \mathrm{~K} 16\end{array}$ & - \\
\hline
\end{tabular}

aspearman correlations, $P \leq 0.05 ;-=$ no significant correlations.

$S D=$ standard deviation $;=$ knowledge domain item number; $B=$ behaviour domain (1 item). 


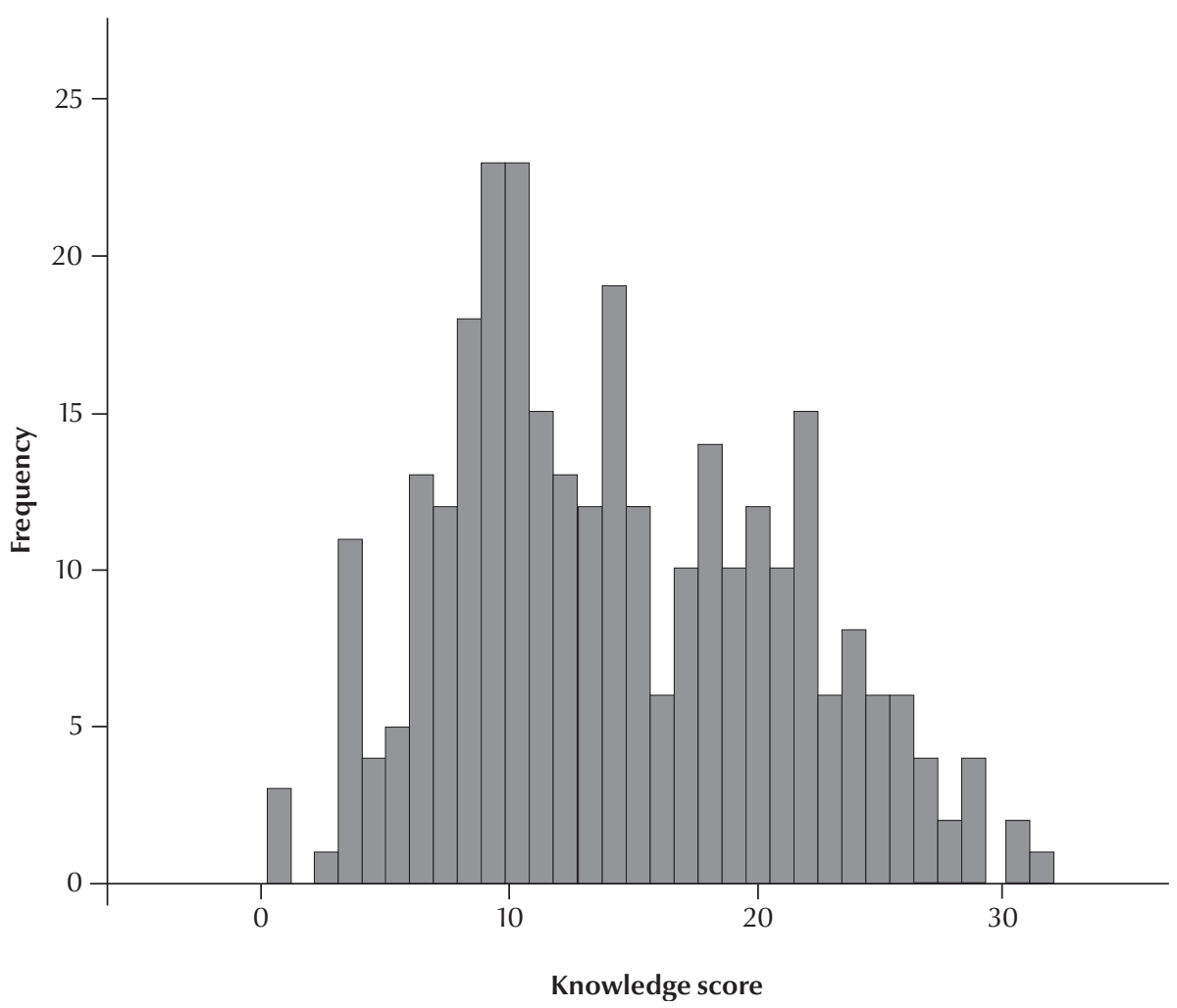

Figure 1 Prevalence (net frequencies) of total knowledge scores obtained by 300 dentists (range of knowledge scores: 0-44)

vaccination and antibody titre (question nos. 12-14), or crucial questions regarding $\mathrm{HBV}$ patients and their management (questions nos. 2, 5, 10, 11, 17, 18) (Table 1). This was similar to the results of Chhabra et al. on medical students (22). Knowledge scores might differ from study to study (4), due to factors such as differences in test difficulties or differences in the target populations (e.g. physicians versus dentists; younger clinicians versus older ones).

Exploring the distribution of responses to each question showed that extreme attitudes were less prevalent and most dentists had positive attitudes. The low percentage of high scores for the attitude items indicated that most dentists were reluctant to treat HBV carriers, although the situation was somewhat better than what was seen concerning AIDS patients in the United Kingdom (UK) (16) and the Islamic Republic of Iran (14). Attitudes seemed to be unaffected by knowledge, although a weak, positive correlation was observed between the categorized knowledge and attitude scores. Exploring the questions individually showed that only a few of the attitude items were correlated with knowledge, especially 3 items that were concerned with transmission of the virus and its prevention.

While a very low proportion of dentists were inclined to treat AIDS patients in the Islamic Republic of Iran (15\%) (14), Canada (23), the United States of America (30\%) and the UK (46\%) (16), hepatitis B is much better perceived by Iranian dentists $(55.6 \%$ agreed to treat unconditionally or conditionally in the present study), Indian medical interns (67\%) (9), American dental students (62\%) (24),

Table 4 Overall percentage knowledge, attitude and behaviour scores (as percentage of maximum obtainable score) towards hepatitis B virus (HBV) among Tehran dentists $(n=300)$

\begin{tabular}{|c|c|c|c|c|c|}
\hline \multirow[t]{2}{*}{ Domain } & \multicolumn{5}{|c|}{$\%$ of maximum scores } \\
\hline & Mean (\%) (SD) & $95 \% \mathrm{Cl}$ & Min. & Max. & Median \\
\hline Knowledge & $32.1(15.7)$ & $30.3-33.9$ & 0.0 & 72.7 & 29.5 \\
\hline Attitude & $51.2(9.3)$ & $50.1-52.2$ & 17.9 & 79.5 & 51.3 \\
\hline Behaviour & $64.3(26.7)$ & $61.2-67.3$ & 0.0 & 100.0 & 75.0 \\
\hline
\end{tabular}

$S D=$ standard deviation; $C I=$ confidence interval for the mean . 


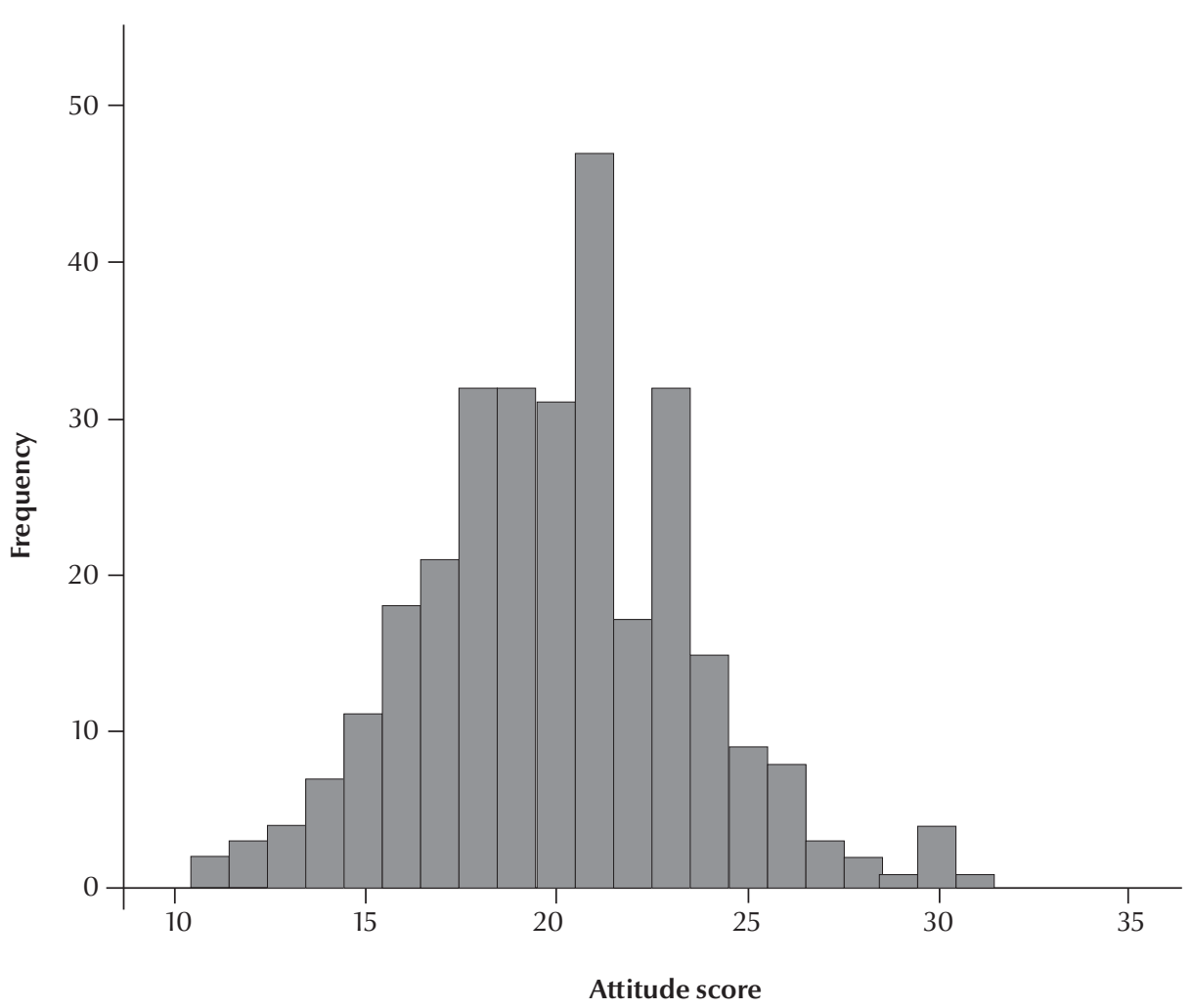

Figure 2 Prevalence (net frequencies) of total attitude scores obtained by 300 dentists (range of attitude scores: 0-39)

Taiwanese dental students (75\%) (25) and Indian dental health-care professionals (66\%) (12). In previous studies (mostly about AIDS) $49 \%$ to $81.1 \%$ of the respondents were willing to treat patients with hepatitis and/or HIV $(8,25)$. This is interesting, since HBV is much more dangerous than HIV in terms of survival, virulence, morbidity and mortality. It might be due to the adverse publicity surrounding AIDS and the fear people might have towards AIDS, or because, unlike HIV, HBV has the potential for vaccination and thus people might be less worried about HBV infection than HIV.

\section{Limitations and strengths}

This study design had some advantages in terms of its methodology compared with other knowledge, attitude and practice (KAP) studies of professionals in different branches of medicine towards any infectious diseases. Other studies have used only mass-survey methods such as posting/handing questionnaires to members of the dental and medical communities, while our study used 2 much more accurate approaches (to interview the dentists one by one, and to check their actual behaviour when encountering a simulated infected patient). Furthermore, our sample size was larger than in many such masssurveyed samples regarding hepatitis B-e.g. 122 dentists (7), 152 dentists (16), 179 dental students (13), 245 dentists (5) - although some studies were larger-e.g. 356 medical staff(including 30 dentists) (10), 356 university students (20), 384 dental students (8) or 540 medical and dental staff (12). These unsupervised methods might lack accuracy and reliability in determining the KAP (14), although rapid methods are still valuable especially when they are carried out on a large sample. Another advantage of this study over our previous study is that we included unregistered dentists who had less experience as well.
It should be noted that no studies have assessed the actual behaviours of dentists but only their self-declared behaviours. On the other hand, our study design was limited due to difficulties in locating each of the offices and visiting them (14). The observers might have been anxious in pretending to be HBVpositive in their earlier visits attempts; these aspects of the study design are explained in detail in our previous article (14). Besides, it was better to assess the reliability of this method by re-evaluating some of the previously evaluated dentists (14). The observers were selected from final-year dental students who were interested in the results, had sufficient time, had good knowledge about hepatitis B, knew about different dental chief complaints that might be needed for visiting the dentists and did not actually have hepatitis B (so that they were not a transmission risk considering their multiple dental visits). These were the advantages of recruiting final-year dental students over recruiting professional 
actors, real hepatitis patients or experienced dentists (14).

It might be argued that some of the dentists in the list overlapped with those assessed previously in our study of KAP towards simulated AIDS patients, and thus they would be alerted about the study protocol. It was not possible for us to check the names of the dentists as names were not recorded in either of the 2 studies. It should be noted, however, that 100 dentists were chosen out of the list of more than 6000 dentists, and, although it is possible, there is a very small chance that some of the dentists were the same ones assessed before. Also the previous study was done about 3 years before this one, which reduces the likelihood of recognizing a simulated patient from the many real hepatitis B patients that attend dental offices.

\section{Conclusions}

The findings indicated that dentists had only poor to moderate knowledge about HBV and although attitudes were a little better they were also scored poor to moderate. Fortunately, unlike our previous study with simulated AIDS patients (14), a majority of the dentists agreed to treat $\mathrm{HBV}$-positive patients. However, many still refused, which is unethical and in some countries even illegal. There was a weak correlation between the categorized knowledge and attitude; however, no other correlations emerged.

\section{Acknowledgements}

The authors sincerely thank colleagues who helped in different phases of this study, which was based on two Doctor of Dental Surgery (DDS) theses, the protocols of which were approved and registered as \#18066 and \#18067 numbers by the internal review board of the Islamic Azad University.

Authors' contributions: Behnam Khosravanifard conceived, designed, and supervised the study. Vahid Rakhshan assisted in the study design, searched the literature, digitized the questionnaire data, designed and performed the statistical analyses, interpreted the findings, and drafted/revised the article. Leili Najafi-Salehi and Samira Sherafat each searched the literature, interviewed the dentists and acted as standardized patients, and calculated/ digitized the scores.

Funding: Self-funded by the authors.

Competing interests: None declared.

\section{References}

1. Resende VL, Abreu MH, Paiva SM, Teixeira R, Pordeus IA. Concerns regarding hepatitis $B$ vaccination and post-vaccination test among Brazilian dentists. Virol J. 2010;7:154. PMID:20626908

2. Ammon A, Reichart PA, Pauli G, Petersen LR. Hepatitis B and $\mathrm{C}$ among Berlin dental personnel: incidence, risk factors, and effectiveness of barrier prevention measures. Epidemiol Infect. 2000 Oct;125(2):407-13. PMID:11117965

3. Word Health Organization. Hepatitis B vaccines. Wkly Epidemiol Rec. 2009 Oct 1;84(40):405-19. PMID:19817017

4. Mahboobi N, Agha-Hosseini F, Mahboobi N, Safari S, Lavanchy D, Alavian SM. Hepatitis B virus infection in dentistry: a forgotten topic. J Viral Hepat. 2010 May;17(5):307-16. PMID:20196802

5. Singh A, Purohit BM, Bhambal A, Saxena S, Singh A, Gupta A. Knowledge, attitudes, and practice regarding infection control measures among dental students in Central India. J Dent Educ. 2011 Mar;75(3):421-7. PMID:21368266

6. Song KB, Choi KS, Lang WP, Jacobson JJ. Hepatitis B prevalence and infection control among dental health care workers in a community in South Korea. J Public Health Dent. 1999 Winter;59(1):39-43. PMID:11396043

7. Veronesi L, Bonanini M, Dall'Aglio P, Pizzi S, Manfiedi M, Tanzi ML. Health hazard evaluation in private dental practices: a survey in a province of northen Italy. Acta Biomed. 2004 Apr;75(1):50-5. PMID:15315087

8. Brailo V, Pelivan I, Škaricić J, Vuletić M, Dulcić N, CerjanLetica G. Treating patients with HIV and Hepatitis B and C infections: Croatian dental students' knowledge, attitudes, and risk perceptions. J Dent Educ. 2011 Aug;75(8):1115-26. PMID:21828306

9. Tirounilacandin P, Krishnaraj S, Chakravarthy K. Hepatitis-B infection: Awareness among medical, dental interns in India. Ann Trop Med Public. 2009;2:33-6.
10. Kabir A, Tabatabaei SV, Khaleghi S, Agah S, Faghihi Kashani $\mathrm{AH}$, Moghimi M, et al. Knowledge, attitudes and practice of Iranian medical specialists regarding hepatitis B and C. Hepat Mon. 2010 Summer;10(3):176-82. PMID:22308136

11. Mahboobi N, Porter SR, Karayiannis P, Alavian SM. Dental treatment as a risk factor for hepatitis B and C viral infection. A review of the recent literature. J Gastrointestin Liver Dis. 2013 Mar;22(1):79-86. PMID:23539395

12. Reddy RS, Swapna L, Ramesh T, Pradeep K. Knowledge, attitude and practice on hepatitis B prevention among dental professionals in India. Braz J Oral Sci. 2011;10:241-5.

13. Sacchetto MS, Barros SS, Araripe TdeA, Silva AM, Faustino SK, da Silva JM. Hepatitis B: knowledge, vaccine situation and seroconversion of dentistry students of a public university. Hepat Mon. 2013;13(10):e13670. PMID:24348639

14. Khosravanifard B, Rakhshan V, Ghasemi M, Pakdel A, Baradaran-Eghbal S, Sheikholeslami R, et al. Tehran dentists' selfreported knowledge and attitudes towards HIV/AIDS and observed willingness to treat simulated HIV-positive patients. East Mediterr Health J. 2012 Sep;18(9):928-34. PMID:23057385

15. Lasemi E, Haddadpour N, Navi F, Rakhshan A, Rakhshan V. Rate of acquired immunity in dental students after hepatitis B vaccination. Dent Res J (Isfahan). 2011 Summer;8(3):128-31. PMID:22013475

16. Crossley ML. An investigation of dentists' knowledge, attitudes and practices towards HIV+ and patients with other bloodborne viruses in South Cheshire, UK. Br Dent J. 2004 Jun 26;196(12):749-54, quiz 780. PMID:15220975

17. Sears B, Ho D. HIV discrimination in health care services in Los Angeles County: the results of three testing studies. Los Angeles (CA): Williams Institute; 2006.

18. Snowden L. An investigation into whether nursing student alter their attitudes and knowledge levels regarding HIV infection and AIDS following a 3-year programme leading to registra- 
tion as a qualified nurse. J Adv Nurs. 1997 Jun;25(6):1167-74. PMID:9181413

19. van de Mortel TF. Health care workers' knowledge of hepatitis C and attitudes towards patients with hepatitis C: a pilot study. Aust J Adv Nurs. 2002 Sep-Nov;20(1):13-9. PMID:12405278

20. Ghahramani F, Mohammadbeigi A, Mohammadsalehi N. A survey of the students' knowledge about hepatitis in Shiraz University of Medical Sciences. Hepat Mon. 2006;6:59-62.

21. Franco E, Bagnato B, Marino MG, Meleleo C, Serino L, Zaratti L. Hepatitis B: Epidemiology and prevention in developing countries. World J Hepatol. 2012 Mar 27;4(3):74-80. PMID:22489259

22. Chhabra P, Grover VL, Agrawal K. Do our medical students have enough knowledge of hepatitis B? A Delhi based study. J Commun Dis. 2002 Sep;34(3):221-5. PMID:14703057
23. McCarthy GM, Koval JJ, MacDonald JK. Factors associated with refusal to treat HIV-infected patients: the results of a national survey of dentists in Canada. Am J Public Health. 1999 Apr;89(4):541-5. PMID:10191798

24. Solomon ES, Gray CF, Gerbert B. Issues in the dental care management of patients with bloodborne infectious diseases: an opinion survey of dental school seniors. J Dent Educ. 1991 Sep;55(9):594-7. PMID:1894830

25. Hu SW, Lai HR, Liao PH. Comparing dental students' knowledge of and attitudes toward hepatitis B virus-, hepatitis C virus-, and HIV-infected patients in Taiwan. AIDS Patient Care STDS. 2004 Oct;18(10):587-93. PMID:15630786 